\title{
Flocculation and Color Removal Performances of Polyacrylamide and Poly N, N-Dimethylacrylamide Grafted Starch: A Comparative Study
}

\author{
Haradhan Kolya, Tridib Tripathy* \\ Postgraduate Division of Chemistry, Midnapore College (Autonomous), Midnapore, India \\ Email address: \\ tridib_tripathy@yahoo.co.in (T. Tripathy) \\ ${ }^{*}$ Corresponding author
}

\section{To cite this article:}

Haradhan Kolya, Tridib Tripathy. Flocculation and Color Removal Performances of Polyacrylamide and Poly N, N-Dimethylacrylamide Grafted Starch: A Comparative Study. American Journal of Polymer Science and Technology. Vol. 3, No. 1, 2017, pp. 1-11.

doi: 10.11648/j.ajpst.20170301.11

Received: October 4, 2016; Accepted: November 24, 2016; Published: February 13, 2017

\begin{abstract}
Starch-g-polyacrylamide (St-g-PAM) and Starch-g- poly (N, N-dimethylacryl amide) (St-g-PDMA) were prepared by using acrylamide (AM) and N, N-dimethylacrylamide (DMA) by Ce (IV) ion induced aqueous polymerization technique. Various grafting parameters were optimized. The so prepared graft copolymers were characterized by fourier transform infrared spectroscopy (FTIR) spectroscopy, molecular weight determination by size exclusion chromatography (SEC), thermal analysis (TGA / DTG), X-ray powder diffraction (XRD) and biodegradation studies. Flocculation performances of the graft copolymers were compared in $1.0 \mathrm{wt} \%$ bentonite clay, $1.0 \mathrm{wt} \%$ coal suspensions and $10 \mathrm{wt} \%$ malachite green (a textile dye) solution and in a textile dye effluent. Between the two polymers St-g-PAM and St-g-PDMA, the later showed better performance in the flocculation of bentonite and coal suspensions but the former showed better performance in the color removal from the malachite green solution and from one of the textile industrial waste water.
\end{abstract}

Keywords: Graft Copolymerization, Starch, Color Removal, Flocculation, Poly (N, N-dimethylacrylamide)

\section{Introduction}

Water pollution caused by domestic waste water, industrial effluents, mineral processing effluents etc. has been worldwide concern due to their hazardous and toxic effects on the environment. Waste water from the varieties of sources contain both dissolved and suspended particles with a wide variety of shapes and sizes, toxic heavy metals and many chemicals, microbiological contaminants adsorbed to the suspended solid particles. Again textile industries utilize varieties of toxic synthetic chemical dyes which are not microbial degraded [1]. Moreover, waste water containing colored substances can inhibit the passage of oxygen and sunlight which are needed for the survival of various aquatic forms [2].

Many chemical processes were used for the treatment of industrial waste water containing dye and particulate matter but the methods are not very much effective in the environmental point of view and in relation to cost $[3,4]$.
Powdered activated carbon, activated bentonites, ozone have been commonly used [1, 4-6]. Another widely used treatment method for dye removal is to use of premixed polyelectrolyte complexes. Such complexes can bind the dye molecules effectively by the electrostatic attraction forces [7, 8]. Hence, from the economic and environmental consideration scientists and technologist were tried to develop materials from plant resources to protect the environment from pollution and to recycle the waste water and industrial effluents for many purposes.

When polymers are involved through the aggregation process to bind the colloidal particles, the process is termed flocculation [9]. In general, flocculation occurs by the addition of a small quantity of chemicals known as flocculants. Among the polymeric flocculants synthetic polymers are very much efficient due to their versatile tailorability which is obtained by controlling their molecular weight, molecular weight distribution, chemical structure etc during their preparation. But the disadvantages of the synthetic polymers come from their non biodegradability and 
shear resistance properties. Again polysaccharides are shear stable, moderately efficient, easily available, inexpensive and biodegradable [10]. But their required dosages for flocculation are large, their solutions and flocs lose stability and strength because of their prone to biodegradation. Thus, it is evident that all the polymers be natural or synthetic, have one or more disadvantages [11].

Grafting of acrylic monomers onto the natural polysaccharides is a process to get materials having various ranges of applications due to the synergistic effect of both the polysaccharide and the synthetic polymers. By grafting polyacrylamide (PAM) chains to the various rigid polysaccharides [12-15], efficient shear stable and controlled biodegradable flocculants were developed for the treatment of industrial waste water, industrial effluents and coal mines water. In these materials, the flexible PAM chains present in the grafted polysaccharides, the approachability of PAM chains to contaminant particles increases significantly [16] due to which they behave as effective flocculants.

Poly (N, N-dimethylacrylamide) (PDMA) is a water soluble and biocompatible synthetic polymer [16]. The graft copolymers of PDMA are used in oil recovery [17] and in flocculation [18-20]. Starch-g-poly (vinyl acetate) has also been reported earlier [21]. In the present investigation an attempt was made to remove a textile dye, malachite green (basic green 4) from its aqueous solution by using PDMA and PAM grafted starch and a comparative study was also made in the same solution. Comparison of their flocculation performances was also done into bentonite and coal suspensions. AM and DMA differs by the presence of two methyl groups at the ' $\mathrm{N}$ ' centre of the latter which is responsible for high polarity of the $-\mathrm{CONMe}_{2}$ group in DMA than that $-\mathrm{CONH}_{2}$ group in AM [22]. Again in polymeric PAM chains intramolecular hydrogen bonding between $>\mathrm{C}=\mathrm{O}$ and $-\mathrm{NH}_{2}$ groups reduce in water solubility but PDMA is easily water soluble because of the absence of intramolecular hydrogen bonding.

\section{Experimental}

\subsection{Materials}

Starch maize (corn) (St) (code: 06117 00500), ceric ammonium nitrate (CAN) (Code: 01122), acetone (code: 0001102500) and acryl amide (code: 0061100100) were procured from Loba Chemie, Bombay, India. N, N- dimethylacrylamide (DMA) (code: 274135) was procured from Aldrich chemical company, St. Louis, USA. Bentonite powder (code: 0178000500) (average particle size: $126.2 \mathrm{~nm}$ and zeta potential $-67.72 \mathrm{mV}$ at $\mathrm{pH} 7.5$ ) was procured from Loba Chemie, Bombay, India. Coal (average particle size: $86.7 \mathrm{~nm}$ and zeta potential $-19.4 \mathrm{mV}$ at $\mathrm{pH}$ 7.2) was obtained from S-seam Bokaro colliery, Bokaro Coal Field, Jharkhand, India. Magnafloc 1011 and percol 181 were obtained from BASF India Limited, Mumbai, India. The detail characteristic properties of bentonite clay and coal samples were given in our previous communication [15]. Malachite green (basic green 4) was obtained from Sisco Research Laboratories Pvt. Ltd, Maharashtra, India. Telfloc 2230 was obtained as a gift from Balaji Paper and Newsprint Pvt. Ltd. Manikpara, W.B, India. One textile industrial effluent was obtained from Srivari Exims Pvt. Ltd. (textile industry), Kolkata, India. N, N-dimethylacrylamide was purified by vacuum distillation and the middle fraction was used for this study. Double distilled water was used for the synthesis.

\subsection{Synthesis of the Graft Copolymers (St-g-PDMA and St-g-PAM)}

The graft copolymers St-g-PDMA and St-g-PAM were synthesized by the Ce (IV) ion induced solution polymerization technique [23]. A typical synthetic procedure of St-g-PDMA was as follows; $2.0 \mathrm{~g}$ Starch was dissolved in $100 \mathrm{ml}$ of distilled water in a $250 \mathrm{ml}$ Erlenmeyer flask. To eliminate any dissolved oxygen into the solution inert $\mathrm{N}_{2}$ gas was purged for $15 \mathrm{~min}$. Then $10 \mathrm{ml}(0.1091 \mathrm{~mol})$ of DMA was added into the solution. Purging of $\mathrm{N}_{2}$ gas was continued for $30 \mathrm{~min}$. Ceric ammonium nitrate (CAN) solution, $25 \mathrm{ml}$ $\left(4.564 \times 10^{-4} \mathrm{~mol}\right)$ was added to the reaction mixture followed by constant purging of $\mathrm{N}_{2}$. The temperature of the reaction was kept constant about $29 \pm 1^{\circ} \mathrm{C}$. The reaction was terminated after $6 \mathrm{~h}$ by the addition of saturated hydroquinone solution. Then the polymer was precipitated by adding excess quantity of acetone. Similarly, St-g-PAM was also synthesized using AM instead of DMA as the monomer. Mixture methanol and water (5:1 by volume) was used to remove homopolymer PDMA and the homopolymer PAM was removed by the solvent extraction using fomamide and acetic acid (1: 1by volume) as the solvent. The graft copolymers were pulverized and shieved after drying in a vacuum oven. The synthetic details are given in Table 1.

Table 1. Synthetic details of the graft copolymers.

\begin{tabular}{|c|c|c|c|c|c|c|c|}
\hline \multirow{2}{*}{ Polymer } & \multicolumn{5}{|c|}{ Optimized grafting conditions } & \multirow{2}{*}{$\begin{array}{l}\text { Percentage Grafting } \\
\text { ratio }(G \%)\end{array}$} & \multirow{2}{*}{$\begin{array}{l}\text { Conversion } \\
\text { (C\%) }\end{array}$} \\
\hline & Substrate (g) & Monomer (mol) & CAN (mol) & Time(h) & Temperature $\left({ }^{\circ} \mathbf{C}\right)$ & & \\
\hline St-g-PAM & 2.5 & 1.07 & $4.56 \times 10^{-4}$ & 3.5 & 35 & 380 & 92.1 \\
\hline St-g-PDMA & 2.5 & 1.07 & $4.56 \times 10^{-4}$ & 3.5 & 35 & 720 & 75.6 \\
\hline
\end{tabular}

\subsection{Effect of Reaction Variables}

To get the maximum yield of the graft copolymers, reaction conditions were optimized by varying reaction parameters like monomer (DMA and AM) concentration, substrate concentration, initiator (CAN) concentration, reaction temperature and reaction time. Following equations [24] were used to calculate various grafting parameters. The results are given in figure 1. 
Conversion $(C \%)=\frac{(w t \text { of graft copolymer }-w t \text { of polysaccharide })}{\text { amount of } D M A / A M} \times 100$
Percentage Grafting ratio $(G \%) \frac{w t \text { of graft polymer }}{w t \text { of polysaccharide }} \times 100$
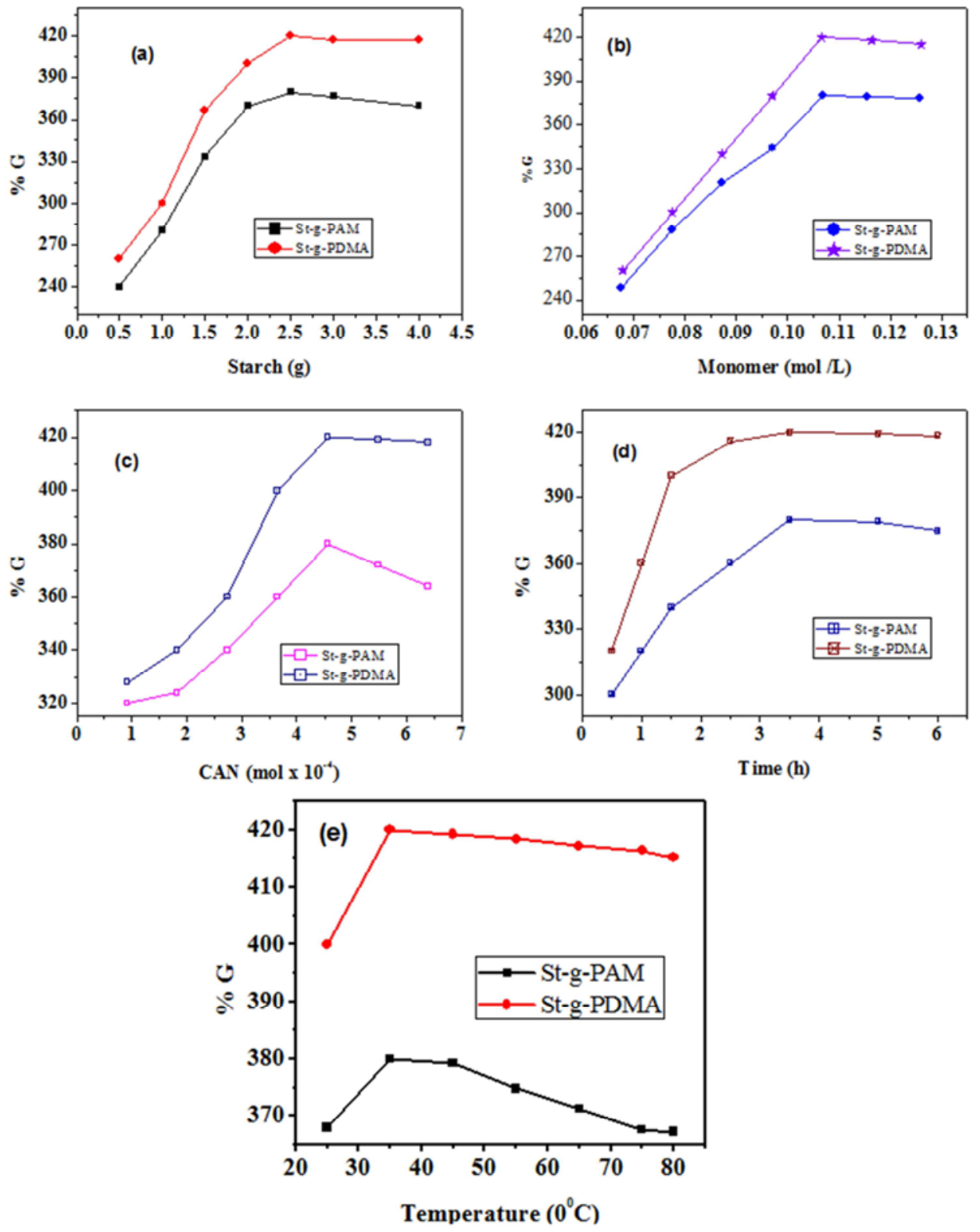

Figure 1. Variation of $G \%$ against (a) concentration of St [condition; monomer $0.107 \mathrm{~mol}$, initiator $4.5 \times 10^{-4}$ mol, time $3.5 \mathrm{~h}$ and temperature $35^{\circ} \mathrm{C}$ ] (b) concentration of monomer [condition; Starch $2.5 \mathrm{~g}$, initiator $4.5 \times 10^{-4} \mathrm{~mol}$, time $3.5 \mathrm{~h}$ and temperature $35^{\circ} \mathrm{C}$ ] (c) concentration of initiator [condition; starch $2.5 \mathrm{~g}$, monomer $1.07 \mathrm{~mol}$, time $3.5 \mathrm{~h}$ and temperature $35^{\circ} \mathrm{C}$ ] (d) reaction time [condition; starch $2.5 \mathrm{~g}$, monomer 1.07 mol, initiator $4.5 \times 10^{-4}$ mol and temperature $35^{\circ} \mathrm{C}$ ] (e) reaction temperature [condition; starch $2.5 \mathrm{~g}$, monomer $1.07 \mathrm{~mol}$, initiator $\left.4.5 \times 10^{-4} \mathrm{~mol}\right]$.

\section{Characterization}

\subsection{Molecular Weight and Molecular Weight Distribution Measurement Using Size Exclusion Chromatography (SEC)}

The molecular weight and molecular weight distribution of St, St-g-PAM and St-g-PDMA were determined using SEC (model: 2414, supplied by water (I) Pvt. Ltd., U.S.A). The flow rate was fixed at $0.6 \mathrm{ml} \mathrm{min}^{-1}$ and the column temperature was kept at $30^{\circ} \mathrm{C}$ during the analysis. The SEC plots of St, St-g-PAM and St-g-PDMA are given in Figs. 2 (a, b, c) respectively. The average molecular weights are given in Table 2 . 

Poly N, N-Dimethylacrylamide Grafted Starch: A Comparative Study

Table 2. Average molecular weight and molecular weight distribution of St, St-g-PAM and St-g-PDMA.

\begin{tabular}{llllll}
\hline Polymer & $\mathbf{M}_{\mathbf{n}}$ (Daltons) & $\mathbf{M}_{\mathbf{w}}$ (Daltons) & $\mathbf{M}_{\mathbf{p}}$ (Daltons) & $\mathbf{M}_{\mathbf{z}}$ (Daltons) & $\mathbf{M}_{\mathbf{z}+1}($ Daltons) \\
\hline St & 87,600 & 906,357 & 933,125 & $9,36,900$ & 967,683 \\
St-g-PAM & $3,095,550$ & $3,899,742$ & $4,468,170$ & $4,820,667$ & $5,995,371$ \\
St-g-PDMA & $8,610,013$ & $9,219,900$ & $9,562,747$ & $9,793,653$ & $10,334,833$ \\
\hline
\end{tabular}

$\mathrm{M}_{\mathrm{n}}=$ numberofaveragemolecularweight, $\mathrm{Mw}=$ weight average molecular weight, $\mathrm{M}_{\mathrm{p}}=$ modeofthemolecularweight distribution/molecular weight of highest peak and $\mathrm{M}_{\mathrm{z}}, \mathrm{M}_{\mathrm{z}+1}=$ higher average molecular weights.

\subsection{FTIR Spectroscopy}

St, St-g-PAM and St-g-PDMA were subjected to FTIR spectral analysis. A Perkin Elmer (L 16000300 Spectrum Two LiTa, Llantrisant, UK) spectrophotometer was used and the potassium bromide $(\mathrm{KBr})$ pellet method was followed for FTIR study. The IR-spectra are shown in figure 2 .

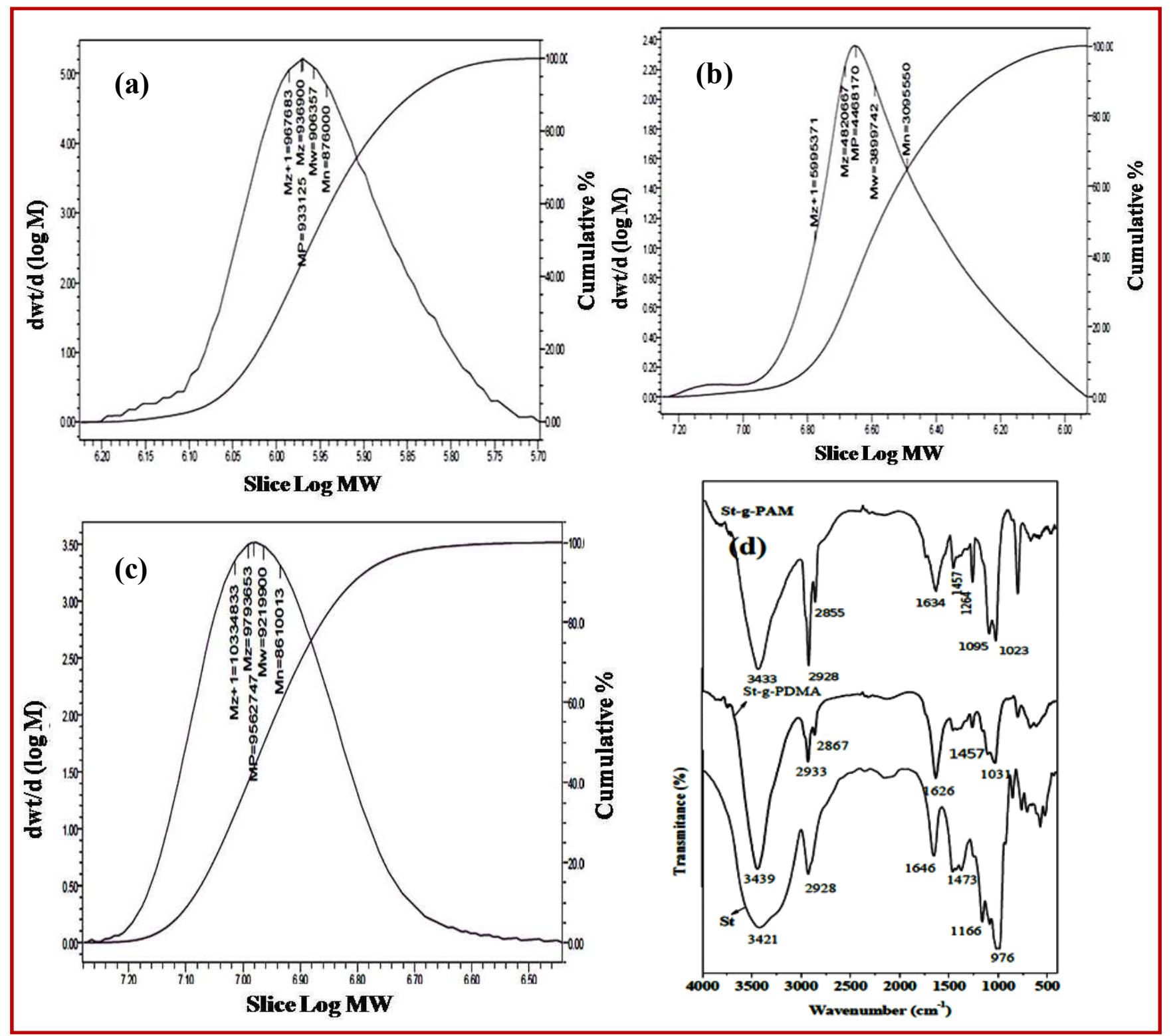

Figure 2. The molecular weight and molecular weight distribution plots of (a) St (b) St-g-PAM (c) St-g-PDMA respectively (d) FTIR spectra of St, St-g-PDMA and St-g-PAM. 

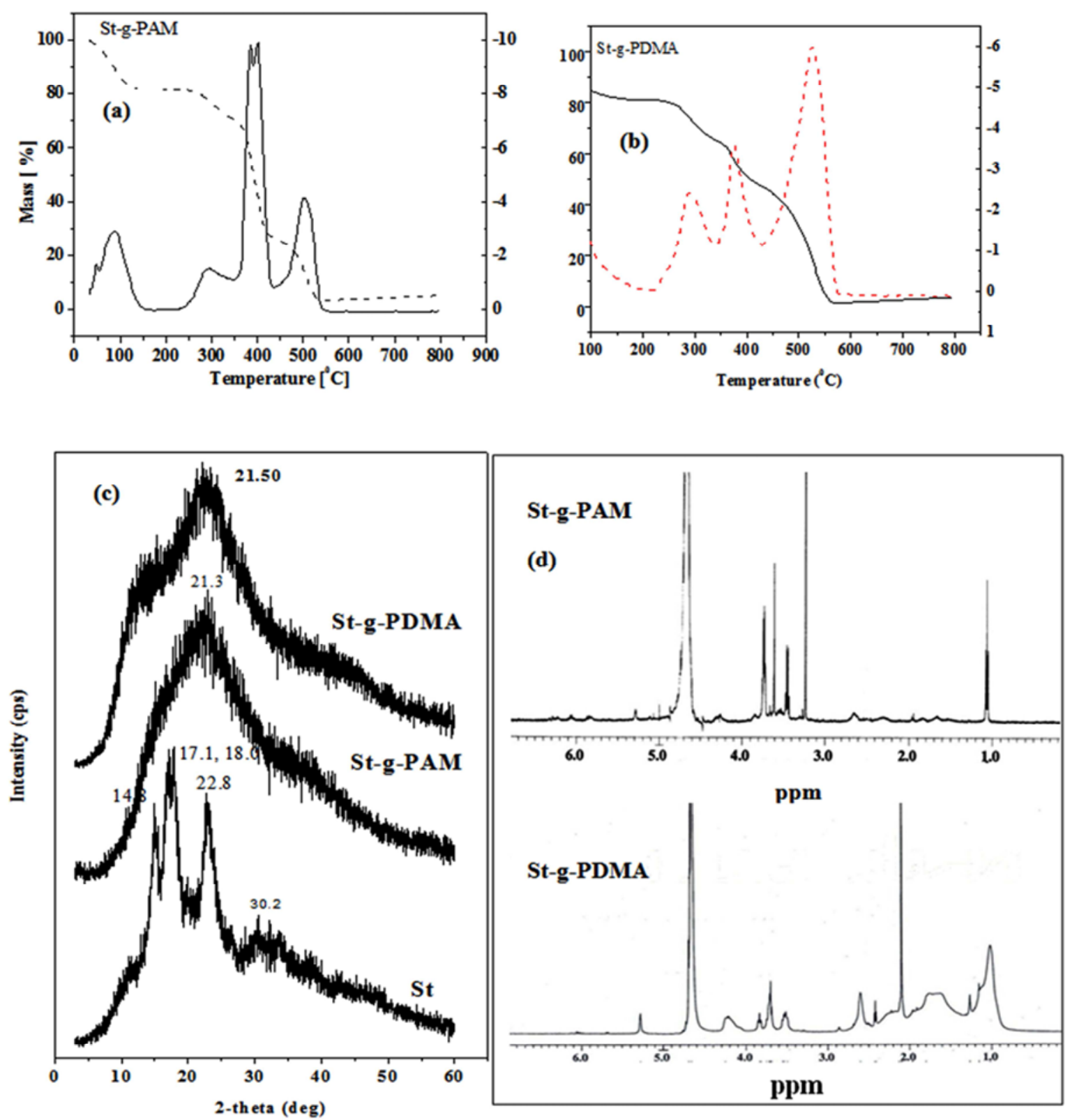

Figure 3. TGA/ DTG curve of (a) St-g-PAM (b) St-g-PDMA (c) XRD plots of St, St-g-PAM and St-g-PDMA (d) ${ }^{l} H$ NMR spectra of St-g-PAM and St-g-PDMA.

\subsection{Thermal Analysis}

The TG / DTG analysis of the graft copolymers St-g-PAM and St-g-PDMA were carried out with Stanton Red Croft (STA625) Thermal Analyzer. Thermal analysis of the compounds was performed up to a temperature of $800^{\circ} \mathrm{C}$ starting from $30^{\circ} \mathrm{C}$ in an atmosphere of nitrogen. The heating rate was uniform in all cases at $10^{\circ} \mathrm{C} \mathrm{min}^{-1}$. The TG / DTG curves are shown in figure 3 .

\subsection{XRD Analysis}

XRD analysis of St, St-g-PAM and St-g-PDMA were performed by 'Rigaku Miniflex-600 (Japan) x-ray diffractometer. Powder XRD was recorded using $\mathrm{CuK} \alpha$ radiation $(\lambda=0.154056 \mathrm{~nm})$. The results are shown in figure 3.

\section{5. ${ }^{1}$ HNMR Spectroscopy}

Purified St-g-PAM and St-g-PDMA were subjected to ${ }^{1} \mathrm{H}$ NMR spectral analysis. The spectra were taken in a $500 \mathrm{MHz}$ NMR instrument (JEOL, Tokyo, Japan) in $\mathrm{D}_{2} \mathrm{O}$ solvent at $25^{\circ} \mathrm{C}$. The spectra are shown in figure $3 \mathrm{~d}$.

\section{Biodegradation Studies of Graft Copolymers}

Biodegradation of the synthesized graft copolymer was performed in sterilized modified Czapex-Dox medium [25] in deionized water. The medium composed by $10 \mathrm{~g} / 1 \mathrm{graft}$ copolymer, $3 \mathrm{~g} / 1 \mathrm{NaNO}_{3}, 1.0 \mathrm{~g} / 1 \mathrm{~K}_{2} \mathrm{HPO}_{4}, 0.05 \mathrm{~g} / 1 \mathrm{MgSO}_{4}$, and $0.00001 \mathrm{~g} / 1$ of $\mathrm{KCl}$ at $\mathrm{pH}$ 5.0. Prepared semisolid plates 
of modified Czapex Dox medium was inoculated with Fusarium sp fungal mycelia and incubated at $28^{\circ} \mathrm{C}$. Plates were observed for fungal growth till 7 days. Fungal growth is shown in figure 4.

\section{Flocculation Studies}

The flocculation Jar test [26] was carried out by using a standard flocculation jar apparatus supplied by Scientific

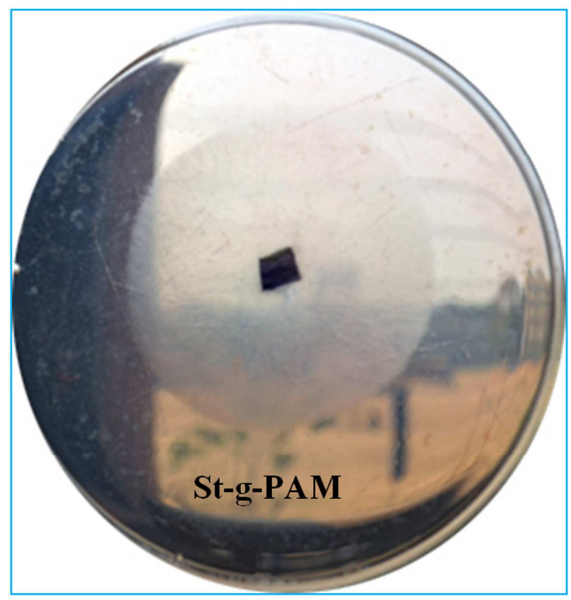

Figure 4. Biodegradation studies on (a) St-g-PAM (b) St-g-PDMA by Fungal (Fusarian Sp) growth.

\section{Color Removal Study}

Color removal from the aqueous solution of basic green 4 was carried out using St-g-PAM, St-g-PDMA. The detail experimental procedure was given in our previous communication [15]. All the adsorption studies were carried out by ultraviolet-visible (UV-VIS) spectrophotometer at $\lambda_{\max } 614 \mathrm{~nm}$. The decolorization efficiency (percentage removal of dye) was calculated by the following equation $[27,28]$.

$$
\text { Decolourization efficiency }=\frac{C_{0}-C}{C_{0}} \times 100
$$

Where $\mathrm{C}_{0}$ is the absorbance of the untreated dye and $\mathrm{C}$ is the absorbance after the treatment with flocculants.

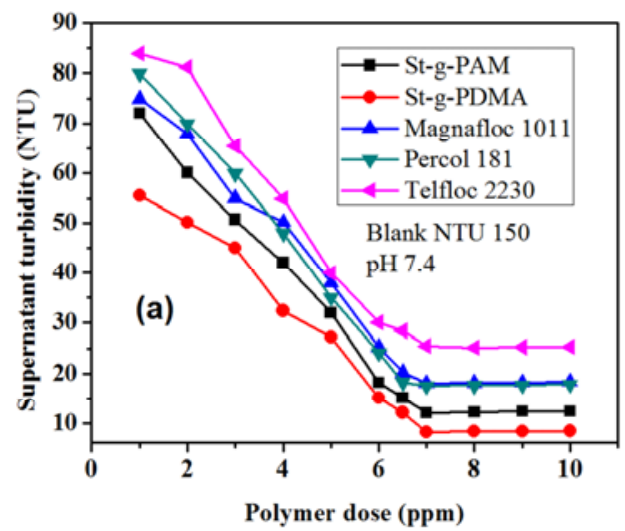

Engineering Corporations (New Delhi, India). Turbidity in nephelometric turbidity unit (NTU) was measured with a digital nephelo turbidity meter (model: 331 ) supplied by EI products (Haryana, India). The detailed flocculation procedure was given in our previous article [27]. Bentonite (1.0 wt \%) and coal (1.0wt \%) suspension were used for flocculation study. The polymer dose was varied from 1-10 ppm for both the suspensions. The results are shown in figure 5.

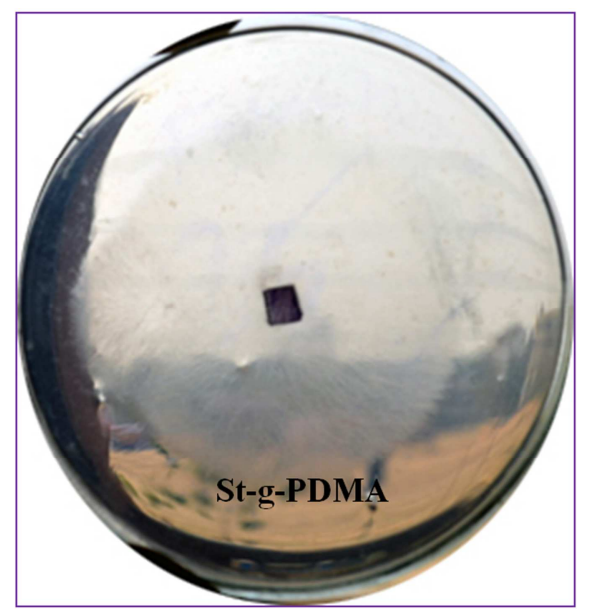

Various operating variables like, the amount of flocculants, solution $\mathrm{pH}$, treatment time and treatment temperature were studied to determine the maximum efficiency of the color removal by the flocculants.

\section{Application of the Graft Copolymers for the Treatment of Textile Industry Waste Water}

In $250 \mathrm{ml}$ beaker, $100 \mathrm{ml}$ of textile waste water was stirred for $10 \mathrm{~min}$ at $350 \mathrm{rpm}$ in absence of flocculent and with 10 ppm of St-g-PAM, St-g-PDMA and commercial flocculants separately. The mixture was allowed to settle for $10 \mathrm{~min}$ and then supernatant was used for UV-VIS spectral studies.

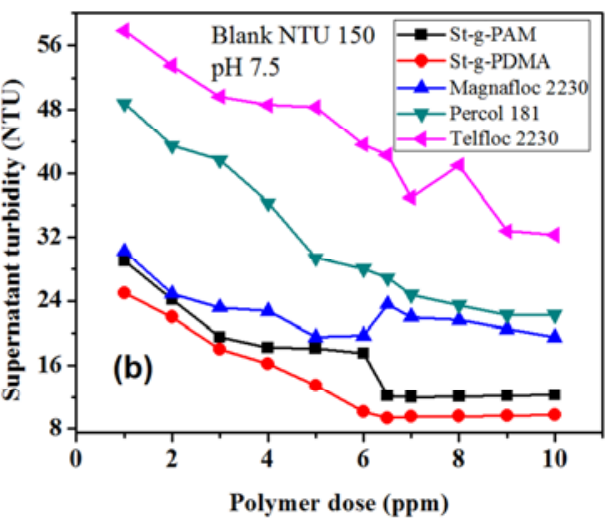

Figure 5. Comparison of flocculation characteristics of (a) St-g-PAM, St-g-PDMA, Magnafloc 1011, Percol 181 and Telfloc 2230 in 1.0 wt\% bentonite suspension (b) St-g-PAM, St-g-PDMA, Magnafloc 1011, Percol 181 and Telfloc 2230 in 1.0 wt\% coal suspension. 


\section{Results and Discussion}

\subsection{Effect of Reaction Variables}

\subsubsection{Effect of the Concentration of Starch}

Percentage grafting ratio $(\mathrm{G} \%)$ increases with increasing the concentration of starch for both AM and DMA up to a certain limit [figure 1 (a)] after that $\mathrm{G} \%$ slightly decreases. The maximum grafting occurs at $2.5 \mathrm{~g}$ of starch. With increasing the amount of starch $\mathrm{G} \%$ increases because of the availability of more (-OH groups) to interact with Ce (IV). Viscosity of the solution increases with increasing further starch concentration which prevents the movements of starch macro radicals [29] leading to decrease in $\mathrm{G} \%$.

\subsubsection{Effect of Monomer Concentration}

Figure 1(b) shows the effect of monomer concentrations of the grafting process. It is evident from the figure that the $\mathrm{G} \%$ increases with increasing monomer concentration up to 0.107 mol / 1 after that G\% decreases. The initial increment is due to greater availability of monomer in the vicinity of polysaccharide macroradicals. During polymerization process the viscosity of the medium increases by graft copolymerization and homopolymerization process. The rate of homopolymerization increases with excess monomer because excess monomers hinder the graft copolymerization resulting lowering the $\mathrm{G} \%$ after the maximum value.

\subsubsection{Effect of Initiator Concentration (CAN)}

Figure 1(c) shows that $\mathrm{G} \%$ increases with increasing CAN concentration up to $4.5 \times 10^{-4}$ mole, after that $\mathrm{G} \%$ decreases in both AM and DMA. The initial increase of $G \%$ with increasing ceric ion concentration is due to the increase in number of free radicals onto the starch backbone. But at higher concentration of CAN ( $>4.5 \times 10^{-4}$ mole) $\mathrm{G} \%$ decreases due to the non availability of starch and also increment of the homopolymerization process by unutilized CAN.

\subsubsection{Effect of the Reaction Time}

From the figure 1(d) it is obvious that G\% increases with increasing reaction time. Maximum grafting occurs at $3.6 \mathrm{~h}$ after that it levels off. The leveling off can be explained by the shortage of the availability of the grafting sites at the polysaccharide backbone during the reaction progress [30].

\subsubsection{Effect of Temperature}

Figure 1(e) shows the effect of temperature onto the grafting. $\mathrm{G} \%$ increases with increasing temperature up to $35^{\circ} \mathrm{C}$ after that it decreases in both AM and DMA. The initial of increment of $\mathrm{G} \%$ up to $35^{\circ} \mathrm{C}$ is due to the increment of diffusion of monomer molecules near the vicinity of the polysaccharide macro radicals. Further rising in temperature, the $\mathrm{G} \%$ decreases due to the increment homopolymrization rate. In every case it is obvious that $\mathrm{G} \%$ is higher in case of PDMA than that of PAM. This is due to better movement of DMA molecules. Acrylamide exits in polymeric association in its solution state by intramolecular hydrogen bonding

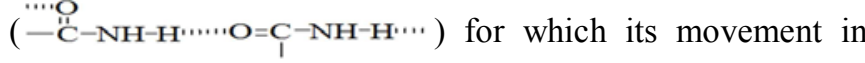
solution phase is sluggish.

The graft copolymers so prepared in optimized condition in which the maximum $\mathrm{G} \%$ is obtained were used for the characterization and the flocculation studies.

\subsection{Characterization of the Graft Copolymers}

\subsubsection{Molecular Weight and Molecular Weight Distribution Using Size Exclusion Chromatography (SEC)}

The molecular weight and molecular weight distribution of St, St-g-PAM and St-g-PDMA were measured using SEC. The molecular weight distribution plots are shown in figure 2. From the molecular weight measurements it is observed that the molecular weight of the two graft copolymers is higher than starch because of the presence of PAM and PDMA chains onto the starch backbone. Again St-g-PDMA grafted starch has higher molecular weight than St-g-PAM due to the presence of two extra methyl groups in amide functionality of DMA molecules. The average molecular weights of St, St-g-PAM and St-g-PDMA are given in Table 2.

\subsubsection{FTIR Spectroscopy}

The FTIR spectra of St, St-g-PAM and St-g-PDMA are shown in figure $2(\mathrm{~d})$. In St-g-PDMA a peak at $1626 \mathrm{~cm}^{-1}$ appears which is for amide $>\mathrm{C}=\mathrm{O}$, peak at $1457 \mathrm{~cm}^{-1}$ is for the $\mathrm{C}-\mathrm{N}$ groups, peak at $3439 \mathrm{~cm}^{-1}$ for $-\mathrm{OH}$ groups present at the starch backbone. The peak at $2867 \mathrm{~cm}^{-1}$ is for saturated C-H units. In St-g-PAM similar peaks are observed at $1634 \mathrm{~cm}^{-1}$ is for amide $>\mathrm{C}=\mathrm{O}, 1457 \mathrm{~cm}^{-1}$ is for $\mathrm{C}-\mathrm{N}$ groups, $2855 \mathrm{~cm}^{-1}$ is for saturated $\mathrm{C}-\mathrm{H}$ units and $3433 \mathrm{~cm}^{-1}$ is for hydroxyl $(-\mathrm{OH})$ groups. Since PAM and PDMA were removed from the graft copolymer completely, presence of amide $>\mathrm{C}=\mathrm{O}, \mathrm{C}-\mathrm{N}$ groups in the graft copolymers is an evidence of grafting.

\subsubsection{Thermal Analysis}

TGA / DTGA curves of St-g-PAM and St-g-PDMA are shown in figure 3 (a) and figure 3 (b) respectively. Four degradation zones are observed in the graft copolymer St-gPAM. The corresponding temperatures are $90^{\circ} \mathrm{C}, 300^{\circ} \mathrm{C}$, $400^{\circ} \mathrm{C}$ and $500^{\circ} \mathrm{C}$. The initial weight loss of the polymer may be due to the absorbed moisture in the graft copolymer. Water is eliminated by the degradation of polysaccharide backbone at $300^{\circ} \mathrm{C}$. Decarbonylation (elimination of $\mathrm{CO}$ ) occurs at $400^{\circ} \mathrm{C}$. The decomposition at $500^{\circ} \mathrm{C}$ is due to the loss of $\mathrm{NH}_{3}$ from PAM chains. In the graft copolymer St-g-PDMA three degradation zones at temperature $300^{\circ} \mathrm{C}, 400^{\circ} \mathrm{C}$ and $520^{\circ} \mathrm{C}$ are observed. At $300^{\circ} \mathrm{C}$ elimination of water by the degradation of starch backbone, at $400^{\circ} \mathrm{C}$ decarbonylation (loss of CO) occurs. The weight loss in the third zone is due to the elimination of $\mathrm{Me}_{2} \mathrm{NH}$ groups from the PDMA chains. From the thermal analysis it can be concluded that PDMA and PAM chains are successfully grafted onto the starch backbone.

\subsubsection{XRD Studies}

The XRD plots of St, St-g-PAM and St-g-PDMA are 
shown in figure 3 (c). From the figure it is obvious that the peaks which are originally present in the starch at $2 \theta=22.8^{\circ}$ shifted to $21.3^{\circ}$ in St-g-PAM, to $27.5^{\circ}$ in St-g-PDMA. This is because of the change in morphology of the polymeric chains after grafting of PAM and PDMA onto the starch. Again, it is obvious that there are three extra peaks which are originally present in the starch at $2 \theta=14.8^{\circ}, 2 \theta=18^{\circ}$ and $2 \theta=30.2^{\circ}$ are completely absent in the graft copolymer which indicating grafting of PDMA and PAM chains in the starch backbone.

\subsection{5. ${ }^{1}$ HNMR Spectroscopy}

Figure 3 (d) shows the ${ }^{1} \mathrm{H}$ NMR spectrum of the graft copolymers St-g-PAM and St-g-PDMA. The spectrum was taken in $\mathrm{D}_{2} \mathrm{O}$ solvent at $25^{\circ} \mathrm{C}$ in which the proton connected to ' $\mathrm{N}$ ' and ' $\mathrm{O}$ ' centers (acidic protons) are exchanged with $\mathrm{D}$ forming $\mathrm{DOH}$. In both cases a very strong signal at $4.7 \mathrm{ppm}$ appears for DOH. In St-g-PDMA the peak at $\delta_{2.4-2.6 \mathrm{ppm}}$ is due to the methyl protons connected to ' $\mathrm{N}$ '. A very sharp signal arises at $\delta_{2.4-2.6 \mathrm{ppm}}$ which is absent in St-g-PAM. The peaks at $\delta_{3.4-3.8 \mathrm{ppm}}$ in both casesare due to the methine $(-\mathrm{CH}<)$ protons of the starch backbone and also for the repeating $\left(-\mathrm{CH}_{2}-\mathrm{CH}<\right)$ unit. The peaks at $\delta_{1.0-1.2 \mathrm{ppm}}$ are due to the $-\mathrm{CH}_{2}$ - protons of the repeating unit present in the grafted chains. In the ${ }^{1} \mathrm{H}$ NMR spectra the disappearance of the peaks of the alkene protons $\left(=\mathrm{CH}_{2}\right)$ at $\delta_{5.8 \mathrm{ppm}}$ and appearance of the signals corresponding to the $\left(-\mathrm{CH}_{2} \mathrm{CH}<\right)$ unit is an evidence of grafting.

\subsection{Biodegradation Study}

The growth of Fusarium sp in the plates observed after 7 days (figure 4). Fungal growth indicates that the fungi have potency to degrade the graft copolymer and utilize as sole
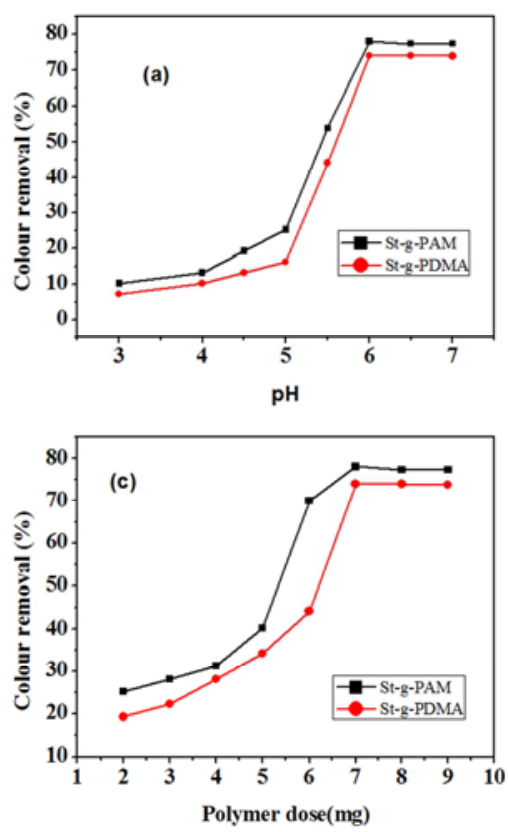

source of carbon. In biodegradation of the graft copolymer, the microorganisms consumes carbons from the graft copolymer as a carbon source and produce energy for cellular activity [31]. It was found that complete degradation occurs at 30-32 days.

\subsection{Flocculation Study}

Figure 5 (a) and 5(b) represent the flocculation performances of synthetic graft copolymer and some commercial flocculating agents in synthetic $1.0 \mathrm{wt} \%$ of bentonite and $1.0 \mathrm{wt} \%$ coal suspension respectively. From the figures it is obvious that the St-g-PDMA shows better performance than St-g-PAM in both the two cases. The reason is as follows; Due to the strong intramolecular hydrogen bonding the grafted polyacrylamide chains in the St-g-PAM becomes stiffen and helical [32]. It is due to the coil and stiffens PAM chains the approachability of the dangling PAM chains to the colloidal particles is the suspensions becomes less. In PDMA chains intramolecular hydrogen bonding is absent due to which the flexibility of the grafted PDMA chains increases. Due to increase in flexibility of the grafted PDMA chains approachability of the grafted PDMA chains on to the contaminant particles also increases resulting easy and intense binding.

The commercial flocculants are polyacrylamide based linear polymers. The graft copolymers have comb like structure for which the approachability of the grafted chains increases to the colloidal particles over the linear polymers to bind the colloidal particles through bridging to form stronger flocs. This explains the better flocculation performance of graft copolymers over commercial flocculants.
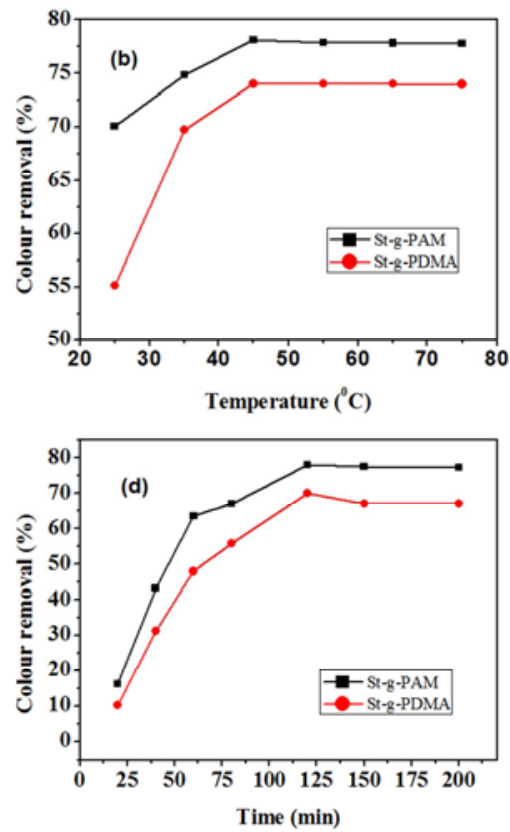

Figure 6. Effect on the color removal (\%) of malachite green (basic green 4) by the flocculants (a) pH (conditions; [basic green 4] 100mg/l, amount of polymer dose $7.0 \mathrm{mg}$, time $125 \mathrm{~min}$, temperature $45^{\circ} \mathrm{C}$ ) (b) reaction temperature (conditions; [basic green 4] $100 \mathrm{mg} / \mathrm{l}$, pH 6.0, time 125 min) (c) polymer dose (conditions; [basic green 4] $100 \mathrm{mg} / \mathrm{l}, \mathrm{pH} \mathrm{6.0,} \mathrm{time} 125 \mathrm{~min}$, temperature $45^{\circ} \mathrm{C}$ ) (d) reaction time (conditions; [basic green 4] $100 \mathrm{mg} / \mathrm{l}$, pH 6.0, polymer dose, temperature $45^{\circ} \mathrm{C}$ ). 


\subsection{Dye Adsorption Dynamics}

Figure 6 shows the effect of $\mathrm{pH}$, polymer concentration, temperature and time onto the decolorization of basic green 4. From the Fig 6(a), it is observed that the percentage color removal by St-g-PAM and St-g-PDMA increases up to $\mathrm{pH}$ 6.0 , after that it remains constant. The maximum adsorption occurs at $\mathrm{pH}$ 6.0. At lower $\mathrm{pH}(<6)$; the amide groups get protonated which generates a positive charge on the polymeric chains. Again in acidic $\mathrm{pH}$ the dye molecule (Basic green 4) also gets protonated resulting positive charges on the dye molecule thus at $\mathrm{pH}<6$, electrostatic repulsion between the graft copolymer and the dye molecule reduces the attraction resulting less adsorption.

From figure 6 (c), it is obvious that the percent color removal increases with increasing polymer dose and reached at equilibrium at $7 \mathrm{mg}$ in each case. This is due to the fact that increasing polymer dose increases the additional adsorption sites which continue up to the equilibrium point, after that, it remains almost constant.

Figure $6(\mathrm{~d})$ shows that the maximum color removal takes place at $125 \mathrm{~min}$. The initial rapid phase may be due to increase in number of vacant sites available at the initial stage, as a result of which there was an increased concentration gradient between the polymers and the dye molecules.
The effect of temperature (figure 6 (b) on the adsorption was studied in the range $25^{\circ} \mathrm{C}-75^{\circ} \mathrm{C}$. It is observed with increase in temperature, sorption of the dye molecules increases up to $45^{\circ} \mathrm{C}$ then it remains constant which indicates endothermic nature of the adsorption.

\subsection{Comparison of the Decolorization Efficiency of St-g- PAM and St-g-PDMA onto Basic Green-4 Solution}

The percentage decolorization efficiency of St-g-PAM and St-g-PDMA onto the dye solution is shown in figure 7 under optimum condition $[\mathrm{pH} 6.0$, polymer dose $7 \mathrm{mg}$, time 125 min, amount of dye $30 \mathrm{ml}(3.0 \mathrm{mg})$, temperature $\left.45^{\circ} \mathrm{C}\right]$. Figure 7 shows the decolurization efficiency of St-g-PAM and St-g-PDMA onto the dye solution. It is obvious from the figure that St-g-PAM shows better performance than St-gPDMA. In St-g-PAM and St-g-PDMA dye molecules are captured by the carbonyl oxygen of amide functionalities present in the grafted chains with the positively charge ' $\mathrm{N}$ ' atom present in the cationic dye molecules. The electron delocalization from the nitrogen atom of the amide group to the carbonyl group increases the electron density on the carbonyl oxygen which reinforces the oxygen atom for making electrostatic attraction onto the cationic nitrogen atom at the dye molecule.

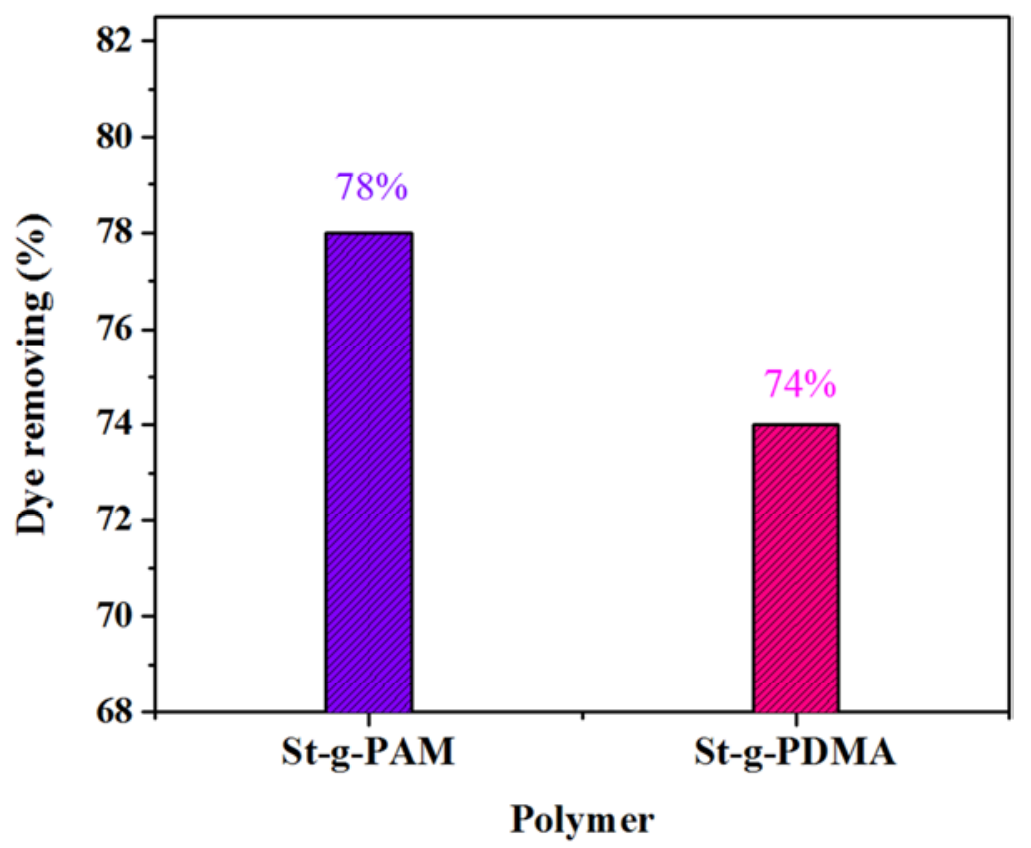

Figure 7. Color removing (\%) efficiencies of St-g-PAM and St-g-PDMA in the malachite green (basic green 4) solution under optimum conditions [(MG) 100 $\mathrm{mg} / \mathrm{L}$, amount of adsorbent $7 \mathrm{mg} / \mathrm{ml}$, time $125 \mathrm{~min}$ and temp $45^{\circ} \mathrm{C}$.

In $\mathrm{N}, \mathrm{N}$-dimethylamide functionalities $\left(-\mathrm{CONMe}_{2}\right)$ due to the presence of large sized methyl groups at the ' $\mathrm{N}$ ' atom the approaching of the dye molecules for the coordination with the carbonyl oxygen becomes difficult than that with amide ($\mathrm{CONH}_{2}$ ) functional groups. Thus, because of the larger size of $-\mathrm{NMe}_{2}$ group over $-\mathrm{NH}_{2}$ group the coordination of dye molecules with $-\mathrm{NMe}_{2}$ group is weaker than that of $-\mathrm{NH}_{2}$ group. Another reasons for better performance of the St-gPAM over St-g-PDMA is the hydrogen bonding effect of $\mathrm{CONH}_{2}$ groups with the counter anion present in the dye

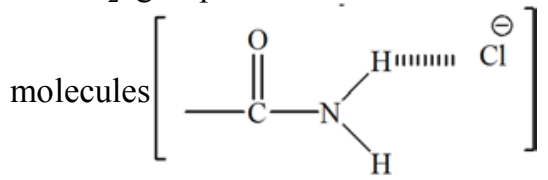




\subsection{Comparison of the Decolorization Efficiency of St-g- PAM and St-g-PDMA in the Waste Water from a Textile Industry}

The plot of absorbance vs wavelength of supernatant collected after the jar test experiments is shown in figure 8 . From the figure it is obvious that graft copolymers (St-gPAM and St-g-PDMA) show better performance (less absorbance value) than the polysaccharide itself and some of the commercially available flocculants. Again between St-gPAM and St-g-PDMA the former shows better performance (lowest absorbance).

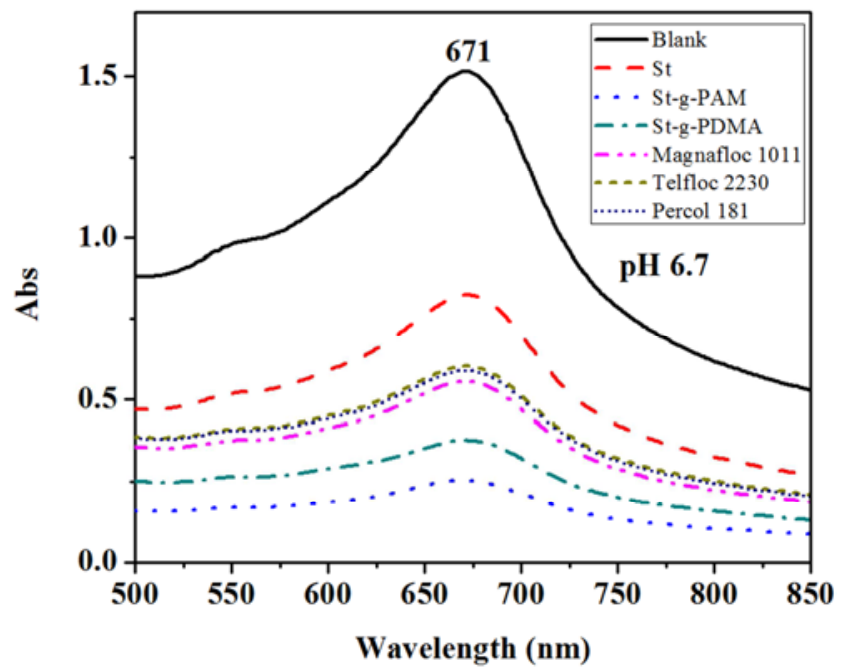

Figure 8. Absorbance against wavelength plots of St-g-PAM, St-g-PDMA, Magnafloc 1011, Percol 181 and Telfloc 2230 in industrial (textile) waste water.

\section{Conclusion}

From the present investigations following conclusions can be drawn. Polyacrylamide and poly (N, Ndimethylacrylamide) chains are successfully grafted onto the starch backbone by ceric ion induced solution polymerization technique. The maximum grafting occurs at starch $2.5 \mathrm{~g}$, monomer concentration 0.107 mole, initiator (CAN) $4.56 \mathrm{x}$ $10^{-4}$ mole, reaction time $3.5 \mathrm{~h}$ and the reaction temperature $35^{\circ} \mathrm{C}$. FTIR spectroscopy, molecular weight determination by SEC, XRD studies supports the formation of the graft copolymers. The graft copolymers are biodegradable. TGA / DTGA results showed different thermal decomposition patterns for the starch and the graft copolymers. St-g-PDMA showed better flocculation performance than St-g-PAM in both the coal and bentonite suspensions but the flocculation performance of St-g-PAM was better when compared with St-g-PDMA for the color removal in a synthetic dye, malachite green (basic green 4) solution and also in a textile industrial waste water. Both the graft copolymers show better flocculation performance than some commercially available flocculants namely magnafloc 1011, percol 181 and telfloc 2230 in both coal, bentonite clay suspensions, malachite green (basic green 4) solution and in the waste water from a textile industry.

\section{Acknowledgements}

The financial support of this research by the West Bengal Department of Science and Technology [contract grant number 868 (Sanc.)/ST/P/S \& T/5G-9/2015] is earnestly acknowledged.

\section{References}

[1] Z. Aksu, Process Biochem, 2005, 40, 997-1026.

[2] G. Crini, Bioresour Technol, 2006, 97, 1061-1085.

[3] C. H. Weng, Y. T. Lin, Y. J. Chin, Y. C. Sharma, Coloration Technol, 2013, 129, 298-304.

[4] G. N. Zaharaddeen, S. B. F. Shikin, A. R. Afidah, J. Chem. Eng. Chem. Res. 2015, 2, 623-633.

[5] A. Pala, E. Tokat, Water Resource, 2002, 36, 2920-2925.

[6] O. Yavuz, A. H. Aydin, Fresenius Environ Bull, 2002, 11, 377-383.

[7] G. Petzold, A. Nebel, H. M. Buchhammer, K. Lunkuitz, Colloid Polym Sci, 1998, 276, 125-130.

[8] H. M. Buchhammer, M. Oelmann, G. Petzold, Melliand Int, 2001, 82, 104-105.

[9] H. Barkert, J. Hartmann, John wiley \& Sons: New York , $1988,5,251$.

[10] R. P. Singh, T. Tripathy, G. P. Karmakar, S. K. Rath, N. C. Karmakar, S. R. Pandey, K. Kannan, S. K. Jain, N. T. Lan, Curr Sci, 2000, 78, 798.

[11] S. K. Rath, R. P. Singh, J. Appl polym Sci. 1997, 66, 17211729.

[12] S. Ghorai, A. Sarkar, M. Raoufi, A. Baran, P. H. Sönherr, S. Pal, ACS Appl. Mater. Interfaces, 2014, 6, 4766-4777.

[13] A. K. Sarkar, A. Pal, S, Ghorai, N. R. Mandre, S. Pal, Carbohydr Polym, 2014, 111, 108-115.

[14] H. Kolya, T. Tripathy, Int J Biol Macromol, 2013, 62, 557564.

[15] D. Sasmal, R. P. Singh, T. Tripathy, Colloids and surf A, 2015, $482,575-584$

[16] K. Katoka, H. Miyazaki, T. Okano, Y. Sakurai, Macromol, 1994, 27, 1061-1062.

[17] C. L. Mc Cormick, G. S. Chen, J Polym Sci Part A Polym Chem 1984, 22, 3633-3647.

[18] H. Kolya, T. Tripathy, J Appl Polym Sci, 2013, 127, 27862795.

[19] H. Kolya, Tripathy, T, Int J Bio Macromol, 2014, 70, 26-36.

[20] D. K. Mishra, J. Tripathy, K. Behari, Carbohydr Polym , 2008, 71, 524-534.

[21] Yongsheng Niu, Hongchun Li, Industrial \& Engineering Chemistry Research, 2012, 51, 12173-12177.

[22] J. Clayden, N. Greeves, S. Waren, P. Worthers, Organic Chemistry, Oxford University Press, UK, 2001, p. 293. 
[23] G. Mino, S. Kaizerman, J Polym Sci, 1958, 31, 242-243.

[24] G. F. Fanta, in: R. J. Cresa (Ed.), Block and Graft Copolymerization, Wiley-Inter Science, New York, NY/London, 1973, p. 1-27.

[25] K. G. Vamsi, M. Susmita, Int J Eng. Res. Appl. 2012, 2, 390399.

[26] J. Bratby, Flocculation and Coagulation, Uplands Press, Croydon, UK, 1980, Chapter 8.

[27] H. Kolya, T. Tripathy, Eur. Polym. J. 2013, 49, 4265-4275.
[28] D. Shubo, G. Yu, Peng T Yen, Colloids Surf. B, 2005, 44, 179-186.

[29] A. A. Berlin, V. N. Kislenko, Prog. Polym. Sci. 1992, 17, 765-825.

[30] D. Prashant, Nirmal K Pandya, P. V. K Patel Sinha, Vijay Kumar Sinha, Int J Polym Mater 2003, 52, 565-571.

[31] A. Pandey, D. Banerjee, Terestrial and Aquatic Environmental Toxicology, 20102, 6, 8-13.

[32] W. M. Kulicke, R. Kniewske, J. Klein, Prog. Polym. Sci. 1982, 8, 373. 